\title{
ESTUDO MACROSCÓPICO DAS ADERÊNCIAS PERITONEAIS PROVOCADAS EXPERIMENTALMENTE EM CÃES
}

\author{
EXPERIMENTAL PERITONEAL ADHESIONS IN DOGS. \\ A MACROSCOPIC STUDY
}

\section{Ricardo Junqueira Del Carlo ${ }^{1}$ Simone Rezende Galvão ${ }^{2}$ Jorge José Rio Tinto ${ }^{2}$ Andressa Cristina Gusmão Pontini ${ }^{3}$ Marco Aurélio Ferreira Lopes ${ }^{2}$}

RESUMO

O trabalho objetivou comparar procedimentos cirúrgicos habituais nas laparotomias como fatores etiopatogênicos de aderências. Justifica-se por ser importante para o cirurgião poder reduzir ou prevenir sua formação naquelas situações em que tal mecanismo possa eventualmente criar novas condições patológicas. Os resultados da pesquisa permitem concluir que potencialmente as áreas isquêmicas são os maiores participantes da gênese de aderências. Foi verificado também que a utilização de medidas hemostáticas induziram a formação de aderências, mas em menor intensidade que a isquemia. A abrasão promovida pela hemostasia com gaze cirúrgica, promoveu irritação que se manifestou pela exsudação e deposição de fibrina, traduzindo-se por aderências observadas aos sete e 15 dias. A lesão cruenta, por não interferir com o mecanismo fibrinolítico, permitiu que o exsudato fibroso fosse lisado, e apenas um animal apresentou, aos 15 dias, aderência de pouca intensidade.

Palavras-chave: aderência, peritônio, cirurgia abdominal, cão.

\section{SUMMARY}

This research was performed in order to study the adhesion formation induced by injury to the peritoneum at the

\begin{abstract}
time of surgery. In the present study ischemia by ligation appears to be the most potent adhesiogenic factor. Serosal injury and drying and the lesions cauterized by electric cautery were forms of serosal injury that induced fibrinous or irreversible adhesions. Adhesions were stimulated when drying was combined with rubbing the tissue with dry gauze. The combinant drying with fibrin enhanced the inicial adhesion. Comparing the four factors, serosal injury was posibly the least likely to cause adhesions. In this type of injury the fibrinolitic mechanism was not inhibited.
\end{abstract}

Key words: adhesion, peritoneal, abdominal surgery, dog.

\section{INTRODUÇÃO}

Trabalhos têm sido realizados no sentido de se estudar meios de prevenir a formação de aderências pós-operatórias, devido a deposição precoce de fibrina. Embora certas pesquisas tenham alcançado algum sucesso, cerca de $50 \%$ dos pacientes humanos têm desenvolvido aderências significantes (WILLIANS et al., 1992). As complicações pós-operatórias são importantes nas espécies humana e eqüina, com menor incidência na canina (ORSHER \& ROSIN, 1993).

\footnotetext{
${ }^{1}$ Médico Veterinário, Docente, Departamento de Veterinária, Universidade Federal de Viçosa (UFV), 36570-000, Viçosa, MG. Autor para correspondência.

${ }^{2}$ Docente, Departamento de Veterinária, UFV.

${ }^{3}$ Discente, Departamento de Veterinária, UFV.
} 
As aderências são primariamente prevenidas pela ativação local da plasmina, que é um potente fibrinolítico. A cascata de ativação da plasmina é iniciada pelo ativador de plasminogênio, que está em grande concentração na superfície externa do peritônio, à nível das células mesenquimais. Pequenas quantidades estão nos vasos sanguiíneos submesoteliais (GERVIN et al., 1973; DORR et al., 1990).

Em alguns tipos de lesão o mecanismo fibrinolítico estará inibido pela deficiência de fatores ativadores, ou pela falta de ativação, e as aderências se formarão (RAFTERY, 1981; WILLIAMS $\boldsymbol{e t}$ al., 1992). Nestas circunstâncias, a ativação do plasminogênio é deprimida somente no local da lesão ou da inflamação peritoneal (ORSHER \& ROSIN, 1993).

As lesões peritoneais induzem a exsudato inflamatório, o qual é rico em fibrinogênio e coagula em poucas horas (MILLIGAN \& RAFTERY, 1974). Se a fibrinólise é inadequada, a migração e proliferação fibroblástica no exsudato fibrinoso inflamatório pode ocorrer, causando aderência permanente (HOLTZ, 1984). Conseqüentemente, reduzindo-se a inflamação estará diminuida a severidade das aderências (LIEBMAN et al., 1992).

A isquemia tecidual é importante fator na etiologia das aderências. Isso deve-se a queda na atividade fibrinolítica peritoneal e submesotelial, fazendo com que a fibrina permanecesse mais tempo no local lesado do que o normal das lesões não isquêmicas (ELLIS, 1962).

A aplicação tópica de plasmina e o uso sistêmico ou local de outros anticoagulantes são ineficazes, porque o efeito fibrinolítico precisa ser localizado na lesão e necessita estar presente por vários dias (DORR et al., 1990).

A lesão diminui a atividade fibrinolítica do peritônio e isto pode causar aderências permanentes, desde que o exsudato fibrinoso não possa ser lisado (GERVIN et al., 1973; RAFTERY, 1981).

Baseados no fato de que a formação de fibrina era um passo vital na gênese da aderência, foi postulado o uso de anticoagulantes na prevenção da mesma. CHALKIADAKIS et al. (1952) encontraram efeitos benéficos da heparina, enquanto COHEN et al. (1983) e FLORÊNCIO et al. (1991) não obtiveram resposta satisfatória.

A extensão do processo inflamatório é determinada basicamente pela intensidade da infiltração de neutrófilos, que gera um infiltrado fibrogênico com formação de fortes aderências constituidas principalmente de colágeno (PEREIRALIMA et al., 1992).
A liberação controlada de dexametasona reduz mas não elimina a formação de aderências no cecum do rato, sendo que esta substância não está aprovada para a instilação peritoneal rotineira após cirurgia abdominal (HOCKEL et al., 1987).

O trauma cirúrgico pode representar resposta inflamatória aguda fibroproliferativa. O resultado final deste mecanismo de reparo podem ser aderências pósoperatórias (LIEBMAN et al., 1992).

Experimentalmente muitas pesquisas tem sido conduzidas para prevenir ou diminuir a formação de aderências. Estas incluem: a interferência na aposição das superfícies serosas lesadas (ARRAJAB et al., 1991); prevenção da resposta inflamatória inicial (DISIMONE $\boldsymbol{e t} \boldsymbol{a l}$., 1988); radicais de oxigênio livres (TSIMOYIANNIS et al., 1989); a dissolução ou remoção precoce do exsudato fibrinoso usando agentes fibrinolíticos (DORR et al., 1990); inibição da formação do colágeno (RIVKIND et al., 1983); e a estimulação da atividade intestinal usando agentes procinéticos (SPRINGALL, 1989).

WINSTON (1980) enfatiza a necessidade de recobrir, sem tensão, áreas desnudas de peritônio. Já SINGLETON et al. (1952) notaram menor índice de aderências, quando não recobriam as brechas peritoneais.

O trabalho teve por objetivo avaliar e comparar procedimentos cirúrgicos habituais praticados em praticamente todas as laparotomias, como fatores etiopatogênicos de aderências. Justificase por ser importante para o cirurgião poder reduzir ou prevenir sua formação naquelas situações em que tal mecanismo possa eventualmente criar novas condições patológicas.

\section{MATERIAIS E MÉTODOS}

O experimento foi conduzido no Departamento de Veterinária da Universidade Federal de Viçosa. Foram utilizadas 24 cadelas adultas, sem raça definida, com peso médio de $12 \mathrm{~kg}$. Todos os animais, após sofrerem os cuidados rotineiros de assepsia e anti-sepsia, foram submetidos à anestesia geral inalatória e à laparotomia mediana retroumbilical de cerca de 12 centímetros.

Os animais foram separados aleatoriamente em quatro grupos iguais, de acordo com o procedimento cirúrgico indutor de aderência utilizado, conforme se segue:

Grupo A: lesão isquêmica. Foram realizadas quatro lesões isquêmicas distando dois centímetros cada, e a cerca de três centímetros da borda 
lateral da ferida abdominal. As lesõs consistiam de esmagamento por pinça hemostática e ligadura com fio de algodão 00, formando um "pólipo" com aproximadamente três milímetros, envolvendo o peritônio parietal e musculatura abdominal;

Grupo B: lesão cruenta. As quatro lesões consistiram de esmagamento por pinça hemostática e escoriação com lâmina de bisturi, envolvendo o peritônio parietal e a musculatura abdominal;

Grupo C: lesão cruenta mais abrasão por gaze. Foi repetido o procedimento realizado no grupo B, sendo adicionada hemostasia e abrasão por gaze.

Grupo D: lesão cruenta cauterizada por eletrocautério. Após os esmagamentos e escoriações foram realizadas quatro cauterizações com o bisturi elétrico, objetivando hemostasia.

O fechamento da cavidade abdominal foi feito em planos, sutura contínua do peritônio e aponeurose com fio de nailon monofilamentar 0 , redução de subcutâneo com o mesmo fio e sutura da pele com nailon monofilamentar $00 \mathrm{em}$ pontos simples separados.

Todos os grupos tiveram dois animais sacrificados aos 7 dias (animais 1 e 2) e quatro sacrificados aos 15 dias (animais de números 3 a 6 ). Para que a cavidade abdominal fosse explorada e pesquisada a presença de aderências, foi realizada uma incisão curva, do gradeado costal à sínfise púbica, com concavidade voltada à direita, de forma a não atingir $\mathrm{a}$ área onde se localizavam os procedimentos geradores de aderências.

Foram utilizados dois critérios para a contabilização das aderências: presença ou ausência das mesmas, o que a tornou independente de variações subjetivas e menos sujeita à erros de avaliação, como pode acontecer nos modelos que necessitam de medições, e que está sujeito a variação individual de cada animal. A cada animal foi atribuido um número de 0 a 4 , de acordo com o número de pontos que apresentassem aderências com as estruturas abdominais. Pelas características macroscópicas e grau de adesão, as aderências foram classificadas em transitórias (T) ou permanentes $(\mathrm{P})$. As aderências fibrinosas foram caracterizadas como transitórias, e as organizadas por tecido fibroso e vasos neoformados, observados macroscópicamente, como permanentes.

\section{RESULTADOS}

Logo após o retorno da anestesia e até o momento do sacrifício o comportamento dos animais nas baias não diferiu do habitual.

$\mathrm{Na}$ observação da cavidade abdominal no momento da necropsia, aos sete e quinze dias de pós-operatório, não se verificou em nenhum animal, indícios de processo inflamatório do peritônio, que exibia seu brilho característico, sem hiperemia ou presença de qualquer líquido ou secreção anormal.

As aderências, quando instaladas (Tabela 1), ocorreram sempre entre o epíplon e a lesão produzida (Figuras 1 e 2). Sobre os pontos que se apresentavam sem aderências, foi observada "peritonização" por fina membrana de tecido, a qual era mais evidente nos animais sacrificados aos 15 dias (Figuras 3 e 4 ).

No grupo D, nos quatro pontos cauterizados pelo bisturi elétrico foram observadas macroscopicamente, durante a necropsia, áreas centrais de necrose, tanto aos sete quanto aos quinze dias de pós-operatório.

\section{DISCUSSÃO}

As aderências peritoneais vêm sendo estudadas a muitos anos com intuito de se verificar uma maneira eficaz de combatê-las. O uso de várias substâncias (HOCKEL et al. 1987; DORR et al. 1990; CHALKIADAKIS, 1952; COHEN et al., 1983; FLORÊNCIO et al., 1991) foi pesquisado porém, ainda sem resultados definitivos.

Tabela I - Núnero de adertencias e curacterizacto destas como pemanente (P) c transitória (T) em eles sazrifiezdos 30507 e is dias, apds os procediencnlos cifúrgicos indutores da ades 10 .

\begin{tabular}{|c|c|c|c|c|c|c|c|c|}
\hline & \multicolumn{2}{|c|}{ GRUPOA } & \multicolumn{2}{|c|}{ GRUPOB } & \multicolumn{2}{|c|}{ GRUPOC } & \multicolumn{2}{|c|}{ GRUPOD } \\
\hline & 7 dias & Is dias & 7 dias & 15 dias & 7 dias & 15dias & 7 dias & 15 dias \\
\hline Animal 1 & $4 P$ & & 0 & & $3 T$ & & 0 & \\
\hline Animal 2 & $4 P$ & & $2 \mathrm{~T}$ & & 0 & & 0 & \\
\hline Animal 3 & & $4 \mathrm{P}$ & & 0 & & $4 \mathrm{~T}$ & & $2 T$ \\
\hline Animal 4 & & $4 P$ & & 0 & & 17 & & 0 \\
\hline Animal 5 & & $4 P$ & & 0 & & $2 T$ & & $2 \mathrm{~T}$ \\
\hline Animal 6 & & $4 P$ & & $1 \mathrm{~T}$ & & 0 & & ir \\
\hline
\end{tabular}




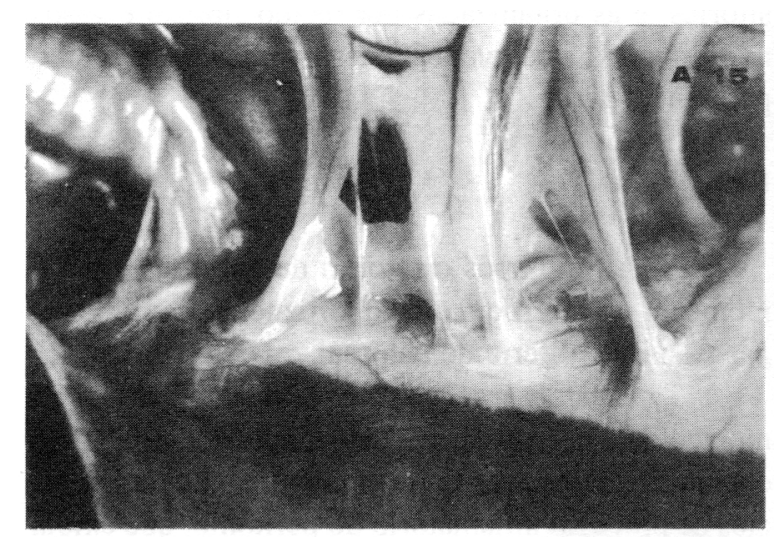

Figura 1 - Aderências do tipo permanente nos quatro pontos de lesão isquêmica, animais do grupo A, 15 dias de pósoperatório.

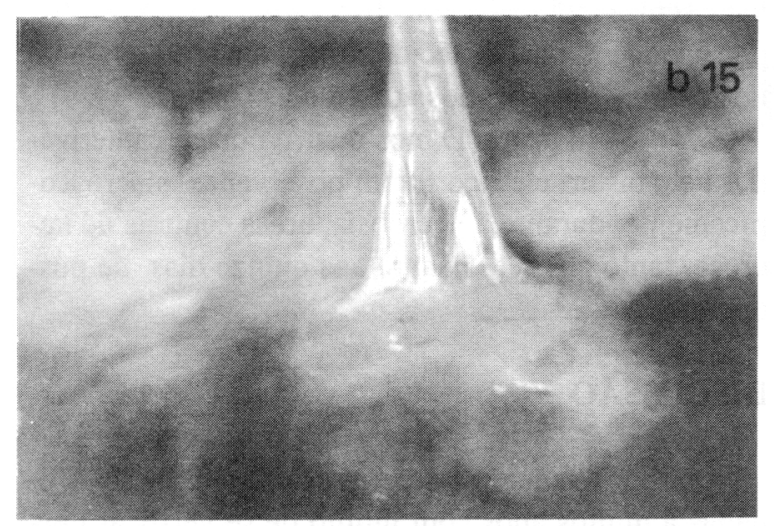

Figura 2 - Aderência do tipo transitória em um ponto de lesão, grupo B, 15 dias de pós-operatório.

As manobras cirúrgicas bem definidas auxiliam o cirurgião na manutenção da anatomofisiologia da cavidade peritoneal de forma mais adequadapossível após a agressão operatória.

Pode-se citar como exemplos, a não realização de ligaduras em massa, evitar os descolamentos exagerados, a reperitonização adequada e a coaptação exata das bordas peritoneais, conforme salientam SIGLETON et al. (1952) e WINSTON (1980).

Os resultados da pesquisa demonstram de forma bem evidente, coincidindo com os dados da literatura (ELLIS, 1962, WINSTON, 1980), que asáreas isquêmicas incrementam a formação de aderências. Isto se deveu provavelmente, a fibrina que permaneceu mais tempo no local lesado do que em lesões não isquêmicas.

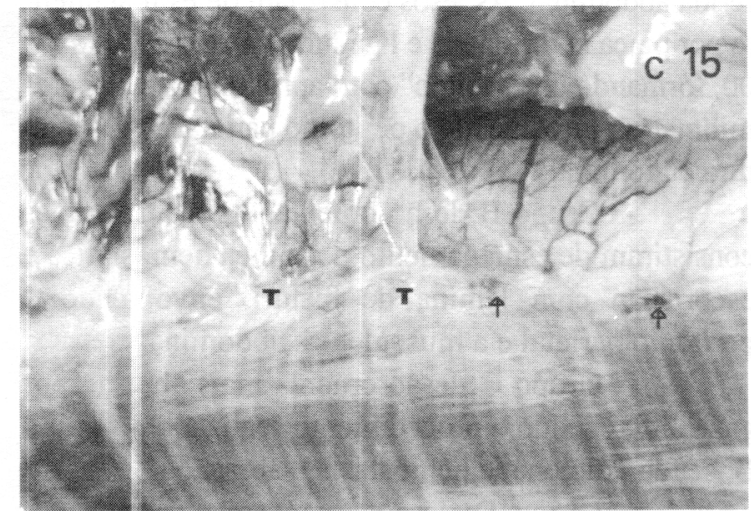

Figura 3 - Pontos de aderência transitória (T) e aéreas de reperitonização (setas), animais do grupo C, sacrificados aos 15 dias.

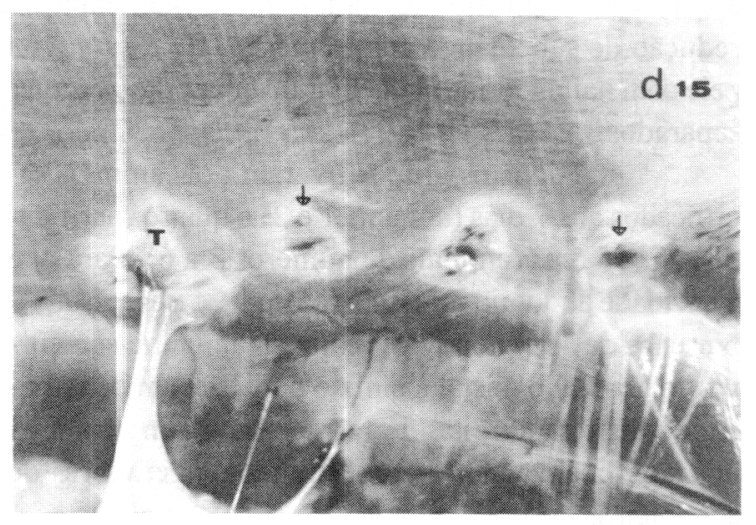

Figura 4 - Áreas de aderência transitória (T) e de reperitonização (setas), animais sacrificados aos 15 dias, grupo D.

Além disso, pode-se verificar que a utilização de medidas hemostáticas desnecessárias podem vir a aumentar os índices destas, visto que nas áreas cruentas a abrasão durante a hemostasia por gaze, induziu reação do tipo inflamatória a qual culminou com a deposição de fibrina e presença significante de pontos de aderência do tipo transitória observadas aos 7 e 15 dias de pós-operatório. Estas aderências não evoluiram para o tipo permanente, provavelmente porque o tipo e magnitude da lesão não foram suficientes para impedir o mecanismo fibrinolítico.

Como citado por TSIMOYANNIS et al. (1989) os radicais livres derivados do oxigênio têm importante papel na patogênese das aderências. Sabese atualmente que a lesão das áreas isquêmicas pode não ocorrer durante o período de hipóxia, mas durante 
o período de reperfusão, quando o oxigênio molecular é reintoduzido nos tecidos.

Nos animais do grupo B, aparentemente, a lesão não foi capaz de destruir o mecanismo fibrinolítico, o que permitiu a reabsorção precoce e espontânea de aderências. Entetanto, não se deve esperar que após a migração e proliferação fibroblástica isso possa acontecer, conforme citado por HOLTZ (1984). Possivelmente, a lise precoce de fibrina nos exsudatos inflamatórios e sangüíneos pode prevenir o crescimento de fibroblastos, embora aderências transitórias possam ser formadas, como observado no grupo C.

O tipo e magnitude da lesão serosa são importantes na gênese das aderências, pois quanto maior a área de isquemia tecidual, maior será a probabilidade de induzirem a aderência. Ficou evidente pelos resultados que, quando a resposta inflamatória inicial foi minimizada (grupo B), a presença de exsudato foi reduzida e a lise da fibrina apesar de retardada não foi impedida, concordando com MILLIGAN \& RAFTERY (1974) e LIEBMAN et al. (1992) quando afirmaram que o exsudato inflamatório é rico em fibrinogênio e coagula-se em poucas horas.

No grupo C, a abrasão pode ser incriminada na gênese das aderências, já que o trauma produzido é traduzido por maior resposta exsudativa, e consequiente deposição de fibrina. Pode-se deduzir também que este tipo de lesão impediu a lise de maneira temporária (aderências transitórias), não permitindo a infiltração colágena (aderências permanentes).

Para RAFTERY (1981) e WILLIANS $\boldsymbol{e} t$

al. (1992) determinadas lesões são capazes de inibir o mecanismo fibrinolítico. O que pode ser observado no caso das lesões isquêmicas, é que além da inibição, esse tipo de lesão é capaz de impedir que as células mesoteliais próximas participem da lise da fibrina.

Os resultados demonstraram que a presença de tecido desvitalizado dentro da cavidade peritoneal, caracterizado pelos pólipos produzidos no grupo A, aumenta a incidência de formação de aderências. No caso do grupo D, apesar de áreas de necrose induzidas no centro da região cauterizada, a irrigação local não estava comprometida, a ponto de inibir a ativação da plasmina, que está em grande concentração na superfície externa do peritônio (GERVIN $\boldsymbol{e t}$ al., 1973; DORR $\boldsymbol{e} \boldsymbol{t}$ al., 1990), além de se saber que a capacidade fibrinolítica do peritônio reside na presença de ativadores do plasminogênio tanto no mesotélio, quanto nos vasos sangüíneos submesoteliais.

Pelos resultados pode ser aferido que quanto maior o trauma cirúrgico e conseqüentemente maior isquemia tecidual, maior a reação inflamatória, e segundo LIEBMAN $\boldsymbol{e t}$ al. (1992) este tipo de resposta aguda é fibroproliferativa, culminando pela formação de aderências pós-operatórias.

\section{CONCLUSÕES}

Nenhum método tem demonstrado, nos modelos experimentais, ser totalmente efetivo na prevenção das aderências pós-operatórias. São princípios que devem ser observados pelo cirurgião: o manuseio meticuloso dos tecidos; uso apropriado de esponjas e compressas, evitando a abrasão; remoção de sangue livre e depósitos de fibrina sobre superfícies serosas; evitar uso excessivo de hemostáticos; evitar isquemia tecidual e remover tecidos desvitalizados; abdominal e, evitar corpos estranhos na cavidade o omento deve ser arranjado de forma a orientar as aderências, nas situações que são desejáveis.

\section{REFERÊNCIAS BIBLIOGRÁFICAS}

ARRAJAB, A., ROZGA, A.B., AHREN, B. Phosphatidycholine prevents postoperative peritoneal adhesions: an experimental study in the rat. Journal of Surgery Research, v. 50, p. 212215, 1991.

CHALKIADAKIS, G., KOSTAKIS, A., KARAYANNACOS, P.E. The effect of heparin upon fibrinopurulent peritonitis in rats. Surgery Gynaecology and Obstetrics, v. 157, p. 257-260, 1952.

COHEN, B.M., HEYMAN, T., MAST, D. Use of intraperitoneal solutions for preventing pelvic adhesions in the rat. Journal of Reproductive Medicine, v. 28, p. 649-653, 1983.

DISIMONE, J.M., MEGUID, M.M., KURZER, M., et al. Indomethacin decreases carrageenan-induced peritoneal adhesions. Surgery, v. 104, p. 788-795, 1988.

DORR, P.J., VEMER, H.M., BROMMER, E.J.P. Prevention of postoperative adhesions by tissue type plasminogen activador (t-PA) in the rabbit. European Journal of Obstetrics \& Gynecology and Reproductive Biology, v. 37, p. 287-291, 1990.

ELLIS, H. The aetiology of post-operative abdominal adhesions. British Journal of Surgery, v. 50, p. 10-16, 1962.

FLORÊNCIO, R.S., BARACAT, E.C., FOCCHI, J., et al. Efeito da heparina na prevenção de aderências pélvicas. Estudo experimental. Revista Paulista de Medicina, v. 109, n. 6, p. 247-251, 1991.

GERVIN, A.S., PUCKETT, C.L., SILVER, D. Serosal hypofibrinolysis: a cause of postoperative adhesions. American Journal of Surgery, v. 1 
HOCKEL, M., OTT, S., SIEMANN, U. Prevention of peritoneal adhesions in the rat with sustained intraperitoneal dexamethasone delivered by a novel therapeutic system. Annals Surgery and Gynaecology, v. 76, p. 306, 1987.

HOLTZ, G. Prevention and management of peritoneal adhesions. Fertility and Sterility, v. 41, p. 497-506, 1984.

LIEBMAN, S.M., LANGER, J.C., MARSHALL, J.S., et al. Role of mast cells in peritoneal adhesion formation. The American Journal of Surgery, v. 165, n. 1, p. 127-130, 1992.

MILLIGAN, D.W., RAFTERY, A.T. Observations on the pathogenesis of peritoneal adhesions: a light and electromicroscopical study. British Journal of Surgery, v. 61, p. 274-280, 1974.

PEREIRA-LIMA, L., KALIL, A.N., RHODEN, E.L., et al. Efeito de drogas antiinflamatórias e antifibrosantes sobre aderências intra-abdominais pós-operatórias, em um modelo animal. Acta Cirúrgica Brasileira, v. 7, n. 1, p. 31-34, 1992.

RAFTERY, A.T. Effect of peritoneal trauma on peritoneal fibrinolytic activity and intraperitoneal adhesion formation. European Surgery Research, v. 13, p. 397-401, 1981.

RIVKIND, A.I., MARSHOOD, M., DURST, A.L. Cianidanol prevents the development of abdominal adhesions in rats. Archives of Surgery, v. 118, p. 1431-1433, 1983.

SINGLETON, A.O., ROWE, E.B., MOORE, R.M. Failure of reperitonealization to prevent abdominal adhesions in the dog. American Surgery, v. 18, p. 789-792, 1952.

ORSHER, R.J., ROSIN, E. Small intestine. In: SLATTER, D. (ed): Textbook of small animal surgery. Philadelphia: Saunders, 1993. v. 1. p. 593-612.

SPRINGALL, R.G., SPITZ, L. The prevention of post-operative adhesions using a gastrointestinal prokinetic agent. Journal of Pediatric Surgery, v. 24, p. 530-533, 1989.

TSIMOYIANNIS, E.C., TSIMOYIANNIS, J.C., SARROS, C.J. The role of oxygen-derived free radicals in peritoneal adhesion formation induced by ileal ischaemia/reperfusion. Acta Chirurgica Scandinava, v. 155, p. 171-174, 1989.

WILLIANS, R.S., ROSSI, A.N., CHEGINI, N., et al. Effect of transforming growth factor $B$ on postoperative adhesion formation and intact peritoneum. Journal of Surgical Research, v. 52 , n. 1 , p. $65-70,1992$.

WINSTON, R.M.L. Reversal of tubal sterilization. Clinical Obstetrics and Gynecology 